\title{
Role and Importance of IoT in the smart city and E-Governance Nadia Al.Muqrashi ${ }^{\mathrm{a}}$ and Muhammad Saqib ${ }^{\mathrm{a}}$
}

In the recent years, developments growth have been rising in utilizing of recent technologies; Smart cities have been furnished with various electronic devices concentrated on Internet of Things (IoT) to be more smarter than before. The Internet of Things is empowered by various emerging technologies such as smart cameras, sensors, wireless communication devices etc. Smart cities are huge systems connected with countless sub-systems, and these systems are depending on the electricity to move the human, things and data to share information. Without electric power and Internet of Things, the smart city cannot be achieved and services cannot be provided. This paper aims to provide a comprehensive concept of IoT, smart city as well as the relationship of Smart Cities to IoT. Moreover, extensive review of the relationship of IoT to the smart city discussed with few instances of services provided by the government using IoT technologies for the citizens. Therefore the objects and applications which come under the IoT technology that can be used to meet the objective of having smart city. In this paper, a thorough literature on the concept of IoT with Smart City and a brief comparison of it in terms of services, challenges and issues is discussed. Also the discussion on the issues faced by service providers with regards to technologies used to equip the citizens with up to date services.

Keywords: Framework; Internet of Things (IoT); E-Government; Smart city and services:

\section{The Concept of Smart City}

Recently, a growing the number of urban areas and cities around the world under concept of smart city; the smart city is there to rise the improvement and increase the digital information and communication technology (ICT). Obviously, recent technologies are using to use multiple sensors in gathering information about events and processes of urban cities and then adoptive those gathered information into digital data.

After that, that information requires to be analyzed and then altered into control information so the efficient responses can be offered appropriately for events. ICT technologies have used to control the infrastructure systems of the urban environments for years in various fields like traffic systems, energy, water and etc. hence, the use of ICT technologies are corporate with the infrastructure service providers to monitor their performance as well as to provide high quality services for the customers to reach their satisfaction which mean the success of the business. (Falconer 2012).

\section{Smart city stratagem}

Earlier it has been observed that most of people are prefer to shift from villages to cities while all the needed services are available and offered for them. However, the remote regions are lacking of some services that the people need which this case considered as main reason of moving the people to the cities. As expected that by year 2030, there will be around 250,000 people are living in the cities more than today which will cause rising on the requests for housing, mobility requirements, changes in the infrastructure as well as providing other various requirements like data, energy and water etc. (Zanella 2013)

Moreover, the main challenges for the mart city's future are: structure change to include multi departmental and multidisciplinary to discover the city's growth and old city that need for changes, those aim to find out a proper solutions for various areas such as environment, economic, social and cultural changes. (Mahmoodi 2016) 
Table2: Some smartest countries in 2012 (Daniel W., 2015)

\begin{tabular}{|c|c|c|c|c|}
\hline $\begin{array}{l}\text { Year } \\
(2000- \\
2009)\end{array}$ & Canada & Israel & Japan & $\begin{array}{l}\text { United } \\
\text { States }\end{array}$ \\
\hline $\begin{array}{l}\text { Educated } \\
\text { population }\end{array}$ & $50 \%$ & $45 \%$ & $44 \%$ & $41 \%$ \\
\hline $\begin{array}{l}\text { Avg. } \\
\text { annual } \\
\text { growth } \\
\text { rate }\end{array}$ & $\begin{array}{l}2.3 \% \\
\left(5^{\text {th }}\right. \\
\text { lowest })\end{array}$ & N/A & $\begin{array}{l}3.2 \% \\
\quad\left(10^{\text {th }}\right. \\
\text { lowest })\end{array}$ & $\begin{array}{l}1.4 \% \\
\text { (lowest) }\end{array}$ \\
\hline GDP & $\begin{array}{c}\$ 39,070 \\
\left(10^{\text {th }}\right. \\
\text { highest })\end{array}$ & $\begin{array}{l}\$ 28,596 \\
\left(12^{\text {th }}\right. \\
\text { lowest })\end{array}$ & $\begin{array}{c}\$ 33,751 \\
\left(17^{\text {th }}\right. \\
\text { lowest })\end{array}$ & $\begin{array}{c}\$ 46,588 \\
\left(4^{\text {th }}\right. \\
\text { highest })\end{array}$ \\
\hline $\begin{array}{l}\text { Population } \\
\text { change }\end{array}$ & $\begin{array}{l}9.89 \% \\
\left(10^{\text {th }}\right. \\
\text { highest })\end{array}$ & $\begin{array}{l}19.02 \% \\
\text { (highest) }\end{array}$ & $\begin{array}{l}0.46 \% \\
\left(6^{\text {th }}\right. \\
\text { lowest })\end{array}$ & $\begin{array}{l}8.68 \% \\
\left(12^{\text {th }}\right. \\
\text { highest })\end{array}$ \\
\hline
\end{tabular}

\section{IoT (Internet of Things)}

IoT has the ability to integrate different systems to offer free access to the available data by groups also to have digital services instead of traditional services. Configuring the architecture of the IoT is a complex task while different technologies and devices are essential to be connected to each other into one layer to be one well-matched system. Observably, the IoT can be invested and deployed to have valued services as well as enhancing the communication technology among the citizens and administration of smart city. (Framework of IoT for smart city, 2017)

Table1: IoT Architectures / Graphic (Vishwajeet H.
Additionally, IoT is a recent revolution of communication technology to provide suitable protocols for having digital communication by the transceivers and micro-controllers through the internet. Furthermore, by using IoT, the internet will be tenacious through providing extensive access among different wireless end devices environment monitoring sensors, vehicles, home applications and etc. Also, the IoT technology is able to deployment and improvements of multiple applications for better quality services and well data use by the citizens and administration. (Shafie-khah, 2016).

Bhide, 2014)

\begin{tabular}{|l|l|l|}
\hline & IoT Application & $\begin{array}{l}\text { Device } \\
\text { Management }\end{array}$ \\
\hline \multirow{2}{*}{ Application } & Binary | JSON - IPSO Objects \\
\cline { 2 - 3 } & & REST APIs \\
\hline \multirow{2}{*}{ Web } & CoAP | HTTP \\
\hline Transfer & DTLS | TLS \\
\hline Internet & UDP | TCP \\
\hline Network & IPv4 | IPv6 | 6LoWPAN \\
\hline
\end{tabular}




\section{Relationship of IoT to the smart city}

IoT (internet of things) covers multiple aspects start from connected cities and homes reaching to the connected roads and cars which hence connected to various devices for using gathered information to offer required services for the customers. Addition to that, in 201012.5 billion of devices were connected to the internet as well as it expected in 2025 that one trillion of connected devices through the internet and specifying smart phones since they considered eyes of the applications in the connected devices.

The smart city, smart transports, smart industries and safety have given stiffness for the future protection while some countries like Europe, America and Asia for enhancing their governments. While they have decided to use IoT technology since it could achieve growth and place among other communication technologies. Furthermore, multiple visions were focusing on the IoT to mention things that relevant to the objects having various features are addressable, locatable, readable and recognizable through the internet and away from the communication techniques (Radio Frequency Identification "RFID", Wireless Local Area Network "WLAN" and Wide Area Network "WAN"). (Yao, 2013)

Moreover, the RFID and network sensor techniques are able to encounter the challenges that are related to the communication and information systems that related to our round environment which leads to generate huge data that should be stored, interpretable and processed. In this model supplies services delivered in a traditional supplies, but because of the internet of things most of the hospitals have been shifted for the patients to be a remote self-monitoring. Using self-monitoring the patients can get their freedom for tracking their health as well as free requirements for emergency situations for them.

The new revolution of IoT of the internet took wide place since it start used widely recently. IoT can be considered as the expanding various services of the internet, since using this technology which provides efficient communication system among all various objects. In addition, the objects can recognize and mange themselves using support of tools such as RFID and wireless sensor network. Mostly, the RFID is used to allocate the identifications for the objects to be recognizable because the radio

frequency identification is more secure identification for tracing vehicles and objects as well. (Susmita, 2013) In recent years, all the cities with various sizes are aiming to be smarter through linking their everyday objects to the internet for enhancing their communication among all those various objects located in different
Internet of Things (IoT) is the best solution to enhance the information communication system for all the objects relevant to particular city and to other cities. Also, the IoT is able to mitigate multiple issues such as traffic management, increasing the costs of energy and pollution although some important difficulties need to be considered while using IoT technology. (Walsh, 2013)

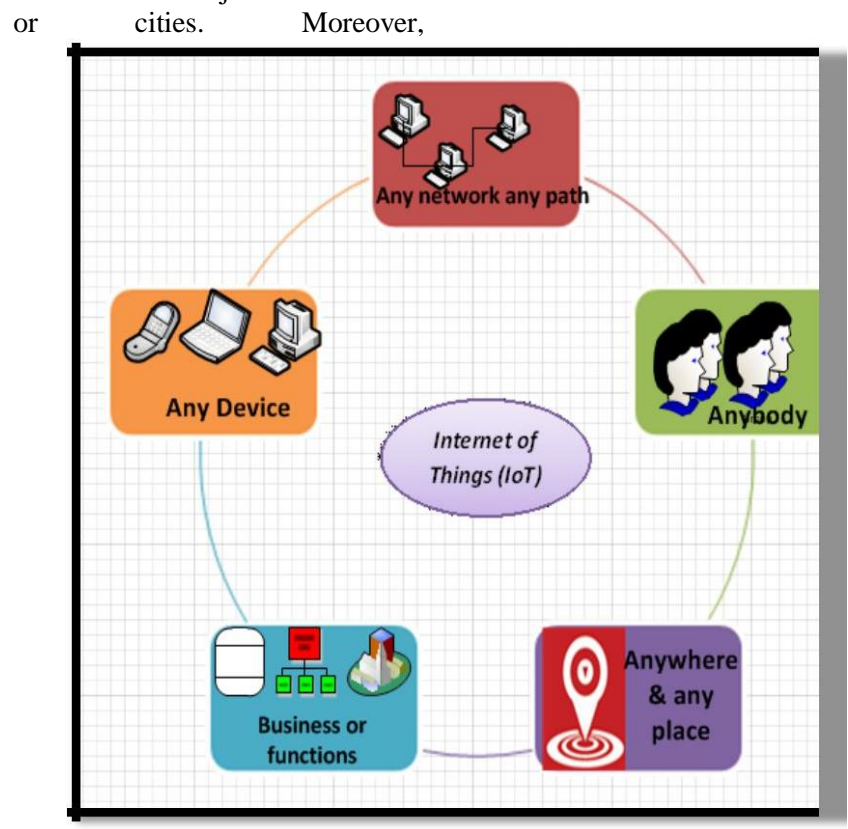


Figure 1. Various objects can communicate to the Internet of Things (IoT).

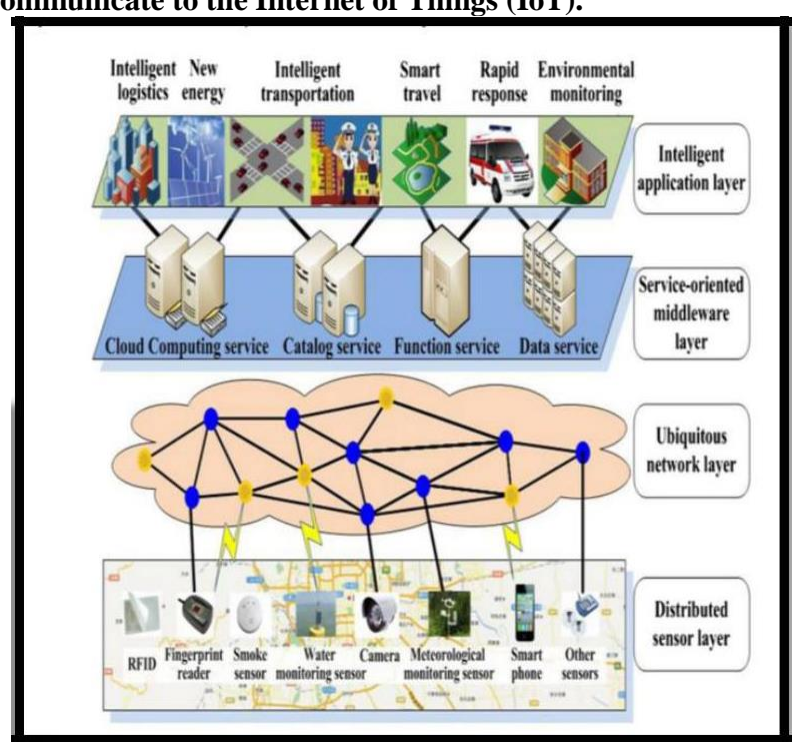

Figure2: A framework of smart city based on the internet of things (Daniel W., 2015).

\section{Analysis a framework of IoT for the smart city}

To have a proper framework for enhancing the cities services to be smarter using IoT technology, first divide the city into parts then analyze resources, kinds and the architecture of all the data as well as standard those data to be merged. Usually, those data can be categorized into three types are (1) background knowledge including important points and roads networks, (2) sensor data involving those data generated by the sensors like air quality, traffic and taxies to be issued and (3) social data that can be generated by users themselves using social media and etc.

Gaining the data of any of those kinds of data for particular decided part of smart city's web services. In addition, it is easy to recognize the features using fusion technologies for creating the knowledge based on founded types of data rendering to the application requirements. Furthermore, using those technologies to define the value of those data as well as to hide the complication of the environment and data resources by representing standard format. (IT-online 2013) As mentioned in the below figure that the IoT technology deployment in the smart city can be separated into multiple levels or layers. First, application layer that are practices in the smart city such as logistics, energy, transportation or smart travel, rapid responses and environmental monitoring all those are services provided by the government to serve the citizens in particular city. Second, service oriented layer which is involves various services provided by multiple servers each is use to enhance particular kind of data of particular services or applications and store those data into the storage of the servers within this layer. Third layer is the network which is handling all those data movement gathered from the sensors among various nodes within the network to be stored and shared between users across different places. Last one is sensors layer, which is responsible to gather data from various sensors like fingerprint reader, camera sensor, smart phones, water monitoring sensor, smoke sensor and etc. then share those data into one central storage in structured format to be understandable and accessible for all the users in the smart city. (Kranz 2017)

\section{Challenges faced by IoT community}

Through deploying the internet of things multiple application domains to be used in various purposes like vehicles communication performance, infrastructure environment, healthcare environment, environment monitoring and etc. However, some challenges and issues are threading the IoT performance such as security since it acts as heart of the internet overall. Therefore, to keep the confidentiality, security and authentication available for the data to be secured even when it is used by users. Addition to that, multiple domains are communicate with each other that leads a huge data generated which need to be stored, managed and provide security for those huge data. Moreover, data transmission through the established transmission line by the source to transfer the data to the destination among the wireless end devices connected to the internet. Those data transmitted are exposed for delay, disruption, hacked or goes to wrong destination which causes traffic and congestion over the network.

\section{The benefits of IoT to the E-Government}

The Internet of Things (IoT) considered as the best technology used to describe the status of physical objects connected to the internet to be able to communicate with each other as well as with various citizens located in different places. Furthermore, IoT takes place in developing the applications and e-services that are E-Government whereas the IoT can provide operational, political, tactical and strategic benefit. Those benefits are permits efficient knowledge sharing and management also integration among various divisions and domains of the organizations as well as among organizations and citizens.

Moreover, online-banking is an instance of e-services of egovernment which required to authenticating the user's confidential details. Also, e-business to be provided for the buyers hence the logistics organizations are responsible to have and secure the user's details since the users don't want to give any confidential details to the vendors or other organizations. Due to this, it is a hard task to have an application used to secure all the user's details while applying to request any kind of online service.

\section{Conclusion}

Hence, proposed solutions for overcoming those challenges and issues in sequence and to avoid the

security challenges of the IoT could be using Software Development network (SDN). Also, to manage the generated data from various applications communications through applying various levels on the urban environment first level for data collection, second level for data processing and third level for data analysis and stored. As well as, the data routing through the internet between wireless end devices become one of the major issues faced by the IoT which can be resolved by Delay Tolerant Network (DTN) (Neisse 2015). In our future work, we are going to work on our proposed framework of SDN and DTN and related technological paradigm. 


\section{References}

Falconer, G. (2012) 'Smart city concepts', Smart City Framework, September.

'Framework of IoT for smart city', The Internet of ThingsEnabled Smart City (March 2017).

IT-Online (2017) 'IoT frameworks', IoT frameworks key to drive value, March.

Kranz, M. (2017) 'IoT infrastructure', Building The Internet of Things, March.

Mahmoodi, A.Z.a.T. (2016) 'framework of IoT for smart city', Semantic Framework of Internet of Things for Smart cities, September.

Neisse, G.S.a.R. (2015) 'IoT security', Aware Scalable and Trust-based IoT Security, Privacy Framework, January.

Shafie-khah, P.S.M. ( 2016) 'Relationship of IoT for smart city', IoT-based Smart Cities, May.

Susmita (2013) 'IoT challenges', Internet of Things and related challenges, June.

Walsh, S. (2013) 'IoT based on smart city', Predix IoT for Smart City Projects, July.

Yao, Y. (2013) A framework of IoT based on smart city, May, [Online], Available: HYPERLINK

"https://www.researchgate.net/figure/258052414_fig 5_Figure-1-A-framework-of-the-smart-city-basedon-the-Internet-of-Things" https://www.researchgate.net/figure/258052414_fig5 _Figure-1-A-framework-of-the-smart-city-based-onthe-Internet-of-Things .

Zanella, L.V.A. (2013) 'Internet of Things', Internet of Things for Smart Cities, April. 